\title{
CARACTERIZACIÓN Y EVALUACIÓN DEL POTENCIAL PGPR DE LA MICROFLORA ASOCIADA AL CULTIVO DE TARWI (Lupinus mutabilis Sweet)
}

\section{CHARACTERIZATION AND EVALUATION OF PGPR POTENTIAL OF THE MICROFLORA ASSOCIATED WITH TARWI (Lupinus mutabilis Sweet)}

\author{
Lucero Huasasquiche Sarmiento ${ }^{1}$, Patricia Moreno Díaz ${ }^{2}$ y Jorge Jiménez Dávalos ${ }^{3}$
}

\begin{abstract}
Resumen
Lupinus mutabilis, 'tarwi', es una especie de gran importancia nutricional y cultural, con características ventajosas en el sector agrícola, probablemente relacionadas a la microflora asociada al cultivo. En este estudio se caracterizó la microflora asociada a sus raíces, tallos, nódulos y rizósfera, según las capacidades PGPR: producción de ácido indol acético, solubilización de fosfatos tricálcicos, producción de sideróforos, antagonismo contra Fusarium oxysporum, fijación in vitro de nitrógeno y promoción de crecimiento en plántulas de tarwi. Los microorganismos fueron aislados de plantas cultivadas en campos de Lima y Jauja, obteniéndose 143 aislamientos de hongos y 190 bacterianos. La cepa fúngica que inhibió un $74 \%$ el crecimiento del patógeno fue identificada perteneciente al género Aspergillus. La prueba de producción de AIA, utilizada como tamizaje inicial, mostró 36 cepas con alta y mediana producción. Con la prueba de solubilización de fosfatos se obtuvo una eficiencia de hasta 4.96; la producción de sideróforos alcanzó una eficiencia de 5.00 y el antagonismo contra el patógeno elegido, una inhibición de hasta 49.3\%. La fijación de nitrógeno más alta fue encontrada en la cepa NR05, con una concentración de $6 \mathrm{mg} \cdot \mathrm{l}^{-1}$ de ion amonio. La mayor parte de los aislamientos bacterianos se identificaron pertenecientes a la familia Bacillaceae. Finalmente, las plántulas inoculadas con la cepa TB05 alcanzaron los mayores valores en altura de planta con un incremento de $10 \%$ comparados al control. Estos resultados sugieren el alto potencial de uso para desarrollar biofertilizantes a partir de estos microorganismos.
\end{abstract}

Palabras clave: Lupinus mutabilis, interacción planta-microorganismo, capacidades PGPR.

\begin{abstract}
Lupinus mutabilis, or tarwi, is a crop with a great cultural and nutritional importance. It has advantageous agricultural characteristics probably related to its native microflora. The aim was to characterize microflora associated with Lupinus mutabilis roots, stems, nodules and rhizosphere. Tests were performed according to PGPR capacities: indol acetic acid (IAA) production, tricalcic phosphates solubilization, siderophores production, antagonism against Fusarium oxysporum, in vitro fixation of nitrogen and tarwi seedlings growth effect. Microorganisms were obtained from plants growing in Lima and Jauja fields; we isolated 143 fungal strains and 190 bacterial strains. The most antagonist fungal strain inhibited $74 \%$ of the pathogen growth which was identified as Aspergillus. The IAA production test was used as initial screening in bacterial isolates, resulting in 36 strains with high and medium production. Then, we obtained up to 4.96 efficiency in phosphate solubilization test; 5.00 efficiency in the production of siderophores and up to $49.3 \%$ of inhibition in the antagonism test against a tarwi pathogen. The highest nitrogen fixation has found in strain NR05 with a concentration of $6 \mathrm{mg} \cdot \mathrm{l}^{-1}$ of ammonium ion. Most of the bacterial isolates identified belong to the Bacillaceae family. Finally, the seedlings inoculated with strain TB05 reached the best values in plant height with an increase of $10 \%$ compared to the control. These results suggest the high potential of use in biofertilizers development from these microorganisms.
\end{abstract}

Key words: Lupinus mutabilis, plant-microorganism interaction, PGPR capacities.

\section{Introducción}

El tarwi (Lupinus mutabilis Sweet) es una leguminosa originaria de la sierra de Bolivia, Ecuador y Perú (Eastwood et al., 2008). En los últimos años, se ha incrementado el interés hacia el lupino como alternativa al consumo de soya, principalmente la de origen transgénico, debido a su alto contenido de proteínas y ácidos grasos (Carvajal-Larenas et al., 2016). Además, es considerado un cultivo muy beneficioso para la agricultura en el altiplano porque 
sus raíces fijan una alta cantidad de nitrógeno atmosférico (400 kg/ha), mejorando así la fertilidad del suelo (Baldomero, 2015); se adapta a diferentes climas de los Andes, encontrándose incluso campos de tarwi por debajo de $\operatorname{los}-4^{\circ} \mathrm{C}$ (Tapia, 2015) y tiene una gran tolerancia al estrés hídrico, similar a la de la quinua (Canahua \& Roman, 2016). Sin embargo, su consumo está siendo disminuido paulatinamente en los países andinos, no sólo por falta de difusión de las formas de uso, sino, también, por el desinterés de las instituciones encargadas de promoverlo (Jacobsen \& Mujica, 2006).

El suelo es un ecosistema con una gran variedad de microorganismos benéficos. En el caso de las bacterias, a aquellas que son beneficiosas para el crecimiento vegetal y son de vida libre se les ha denominado Plant Growth Promoting Rhizobacteria o, por sus siglas en inglés, PGPR (Kloepper, 1993). Éstas influyen directamente en el desarrollo vegetal, a través de la síntesis de distintos compuestos o, indirectamente, evitando el ataque de organismos patógenos.

Múltiples estudios han demostrado la presencia de microorganismos endófitos en interacción con los nódulos del género Lupinus, tales como Micromonospora, actinobacteria fijadora coexistiendo con Bradyrhizobium (Trujillo et al., 2007); Paenibacillus lupini (Carro et al., 2014) y Cohnella lupini (Flores-Félix et al., 2014) en Lupinus albus; Bosea lupini, alfa proteobacteria asociada con L. polyphyllus (De Meyer \& Willems, 2012); Kribbella lupini, Micromonospora lupini y Micromonospora saelicesensis, actinobacterias aisladas a partir de nódulos de Lupinus angustifolius (Trujillo et al., 2006a, 2010). La ocurrencia de estas bacterias en nódulos de Lupinus, y la carencia de reportes dirigidos al estudio de la interrelación microorganismo-planta con Lupinus mutabilis, nos lleva a plantear la necesidad de conocer el estado de la microbiota presente en el tarwi, la cual puede jugar un papel importante en la promoción de crecimiento vegetal.

El objetivo de esta investigación fue aislar cepas de rizósfera, raíces, tallos y nódulos de Lupinus mutabilis y caracterizarlas por sus capacidades PGPR. Del mismo modo planteó identificar molecularmente a los aislamientos con mejores capacidades y evaluar la influencia de ellos en plántulas de Lupinus mutabilis bajo condiciones de invernadero.

\section{Materiales y Métodos}

Muestreo y desinfección de material vegetal

Los plantones de Lupinus mutabilis (Sweet) se colectaron de dos campos pertenecientes a la Universidad Nacional Agraria La Molina: el IRDSierra (11 ${ }^{\circ} 51^{\prime} 22^{\prime}$ ' S 7523'38' W) y al Programa de Cereales y Granos Nativos (1204'40.8' S 7656’37.7'” W).

Para extraer los plantones se delimitaron superficies cuadradas de $20 \times 20 \mathrm{~cm}^{2}$ en cada base y se excavaron hasta obtener la raíz completa $(\sim 50 \mathrm{~cm})$. El suelo no rizosférico fue separado agitando moderadamente la muestra. Luego, se recolectó el suelo más próximo a las raíces en bolsas estériles, con la ayuda de una brocha desinfectada en alcohol $96^{\circ}$. Se colectaron también 10 raíces, 10 tallos y 10 nódulos por planta, los cuales fueron lavados con agua potable y colocados en recipientes con agua estéril (Pérez et al., 2010). La desinfección superficial consistió en un enjuague de 12 horas con agua estéril, un remojo de 2 minutos en solución de bicloruro de mercurio $\left(\mathrm{HgCl}_{2}\right)$ al $2.5 \%$ y 5 enjuagues en agua destilada estéril para remover todo el bicloruro de la superficie (Trujillo et al., 2006b). Se tomaron al azar 5 raíces, 5 tallos y 5 nódulos que fueron transferidos a una placa con medio agar nutritivo para confirmar la ausencia de microorganismos en la superficie.

Aislamiento de microorganismos

Se tomaron $10 \mathrm{~g}$ de suelo rizosférico que fueron transferidos a un matraz con $90 \mathrm{ml}$ de solución salina 0.85\% (León, 2014) agitándose de manera vigorosa (dilución $10^{-1}$ ). Los tallos y raíces desinfectados fueron cortados en secciones de 4-5 cm y macerados en $30 \mathrm{ml}$ de solución salina $0.85 \%$ mientras que los nódulos fueron triturados con $1 \mathrm{ml}$ de solución salina $0.85 \%$ (Claros \& Ortuño, 2013). En un eppendorf estéril se recuperó $1 \mathrm{ml}$ del macerado de cada muestra. Se realizaron diluciones seriales para cada muestra y se inocularon $0.1 \mathrm{ml}$ de las diluciones $10^{-4}$ a $10^{-6}$ en medio AN (agar nutritivo) para bacterias, y medio OGY (agar oxitetraciclina-glucosa-extracto de levadura) suplementado con cloranfenicol 150 ppm, para hongos.

\section{HONGOS}

Antagonismo frente a un patógeno

Las pruebas de enfrentamiento con el patógeno se realizaron mediante la técnica de cultivo dual in vitro (Fernández \& Suárez, 2009; Martínez et al., 2014). Se cortaron fragmentos de $1 \mathrm{~cm}^{2}$ del micelio de los aislamientos, previamente sembrados en medio PDA (agar papa-dextrosa) e incubados a $28{ }^{\circ} \mathrm{C}$ durante 4 días. Cada fragmento fue colocado en un extremo de la placa Petri y se incubó en oscuridad durante 12 horas. Transcurrido ese tiempo, se colocó, en el otro extremo de la placa, un fragmento de $1 \mathrm{~cm}^{2}$ del micelio de la cepa patógena (Fusarium oxysporum), que también fue sembrada previamente en medio PDA a $28{ }^{\circ} \mathrm{C}$ durante 4 días (Zúñiga, 2007). Como control se sembró en medio PDA únicamente al hongo patógeno, considerando su radio como "crecimiento libre (CL)". Las cepas que inhibieron el crecimiento del micelio fueron consideradas como positivas y se midió el radio del hongo, considerándolo como "crecimiento influenciado (CI)".

El porcentaje de inhibición se calculó mediante la Fórmula 1, descrita por Fernández \& Suárez (2009). 
$\%$ de inhibición $=((\mathrm{CL}-\mathrm{CI}) \div \mathrm{CL}) \times 100$

Fórmula 1. Porcentaje de inhibición.

Identificación microscópica

Sólo las que resultaron positivas para la prueba de antagonismo fueron identificadas mediante microscopía hasta nivel de género. Para ello, fueron sembradas en cámara húmeda con medio de cultivo OGY suplementado con cloranfenicol $150 \mathrm{ppm}$, se incubaron durante 5 días y se tiñeron las estructuras fúngicas con azul de metileno. Cada preparación fue observada en un microscopio óptico a $40 \mathrm{X}$ y la identificación se basó en claves taxonómicas de la base de datos online MycoBank (2016).

\section{BACTERIAS}

Producción de ácido indol acético (AIA)

Esta prueba fue un tamizaje para reducir la cantidad de aislamientos bacterianos provenientes de raíces, tallos y rizósfera, aquellos que resultaron negativos o con baja producción de AIA fueron descartados.

La técnica colorimétrica utilizada fue la descrita por (Gordon \& Weber, 1950). Se inocularon las cepas bacterianas a una concentración aproximada de $10^{8}$ ufc. $\mathrm{ml}^{-1}$ en tubos con $4 \mathrm{ml}$ de medio LMC (caldo manitol-levadura) suplementado con L-triptófano $1 \mathrm{~g} \cdot 1^{-}$ ${ }^{1}$ (Marca CDH). El control positivo consistió en LMC con adición de AIA $40 \mathrm{mg} \cdot \mathrm{l}^{-1}$ (Marca CDH) y el control negativo únicamente en LMC. Los tubos se incubaron en oscuridad a $28{ }^{\circ} \mathrm{C}$ durante 5 días. Culminado el tiempo se centrifugaron a $4000 \mathrm{rpm}$ durante $15 \mathrm{~min}$ (Clavijo et al., 2012). La reacción se realizó en microplacas con una proporción muestra:reactivo de 1:2 (Lara et al., 2011): $100 \mu$ del sobrenadante con 200 $\mu 1$ del reactivo de Salkowsky $\left(\mathrm{FeCl}_{3}\right.$, agua destilada y $\mathrm{HSO}_{4}$ en proporción volumétrica 1:50:30), y se incubó 30 minutos a temperatura ambiente, luego se evaluó el viraje de color de la solución a tonalidades rojizas. Se consideró tres niveles cualitativos de producción: nivel bajo (+), nivel medio (++) y nivel alto (+++).

Solubilización de fosfato tricálcico

Los aislados fueron sembrados en medio NBRIP (National Botanical Research Institute's Phosphate, composición para 11:10 g glucosa, $5 \mathrm{~g} \mathrm{Ca}_{3}\left(\mathrm{PO}_{4}\right)_{2}, 5 \mathrm{~g}$ $\mathrm{MgCl}_{2} .6 \mathrm{H}_{2} \mathrm{O}, 0.25 \mathrm{~g} \mathrm{MgSO}_{4} .7 \mathrm{H}_{2} \mathrm{O}, 0.2 \mathrm{~g} \mathrm{KCl}, 0.1 \mathrm{~g}$ $\left(\mathrm{NH}_{4}\right)_{2} \mathrm{SO}_{4}$, $)$ e incubados a $28{ }^{\circ} \mathrm{C}$ durante 5 días. La positividad de la prueba se evidenció por la presencia de un halo transparente alrededor de las cepas (Nautiyal, 1999). Se midió el diámetro del halo hasta observar un valor constante y se calculó la ERS (eficiencia relativa de solubilización) mediante la Fórmula 2, en donde DH es el Diámetro del halo y DC el Diámetro de la colonia. Este índice indica el radio de acción de la bacteria sobre el sustrato en relación al crecimiento de la colonia, expresado en "número de veces mayor a".
$\mathrm{ERS}=\mathrm{DH} \div \mathrm{DC}$

Fórmula 2. Eficiencia Relativa de Solubilización.

Antagonismo frente a un patógeno

Las pruebas de enfrentamiento con el patógeno se realizaron siguiendo el protocolo descrito anteriormente para hongos, con la diferencia de que las cepas bacterianas se sembraron inicialmente en medio PDA y se incubaron a $28{ }^{\circ} \mathrm{C}$ durante 24 horas. El porcentaje de inhibición se calculó mediante la Fórmula 1.

Producción de sideróforos

La producción de sideróforos se determinó siguiendo el método descrito por Schwyn \& Neilands (1987). Las cepas bacterianas fueron sembradas en medio CAS (Agar Cromoazurol Sulfonato; composición para 11 de base: $20 \mathrm{~g}$ proteasa, $1.5 \mathrm{~g}$ $\mathrm{MgSO}_{4} .7 \mathrm{H}_{2} \mathrm{O}, 1.5 \mathrm{~K}_{2} \mathrm{HPO}_{4}$, composición para $100 \mathrm{ml}$ de tinte azul: $0.06 \mathrm{~g}$ CAS en $50 \mathrm{ml}$ de agua destilada, $0.0027 \mathrm{~g} \mathrm{FeCl}_{3} .6 \mathrm{H}_{2} \mathrm{O}$ en $10 \mathrm{ml}$ de $\mathrm{HCl} 10 \mathrm{mM}, 0.0073$ $\mathrm{g}$ de CTAB en $40 \mathrm{ml}$ de agua destilada) e incubadas a $28{ }^{\circ} \mathrm{C}$ durante 5 días. La formación de un halo naranja a amarillo alrededor de las colonias confirmó la producción de sideróforos. Se midió el diámetro de los halos a los 6 días de incubación y se evaluó la ERP (eficiencia relativa de producción) mediante la Fórmula 3, donde DP es el Diámetro de producción y DC es el Diámetro de crecimiento.

$$
\mathrm{ERP}=\mathrm{DP} \div \mathrm{DC}
$$

Fórmula 3. Eficiencia Relativa de Producción.

\section{Fijación de nitrógeno in vitro}

Esta prueba se realizó únicamente en las cepas bacterianas aisladas de nódulos. Se las inoculó en tubos con $3 \mathrm{ml}$ de LMC e incubadas a temperatura ambiente por 72 horas en agitación constante (200 rpm). Transcurrido el tiempo, se agregaron $9 \mathrm{ml}$ de $\mathrm{KCl} 2 \mathrm{M}$ con agitación a 150 rpm durante 1 hora. Se dejó reposar una hora adicional y se tomó $10 \mathrm{ml}$ del sobrenadante para centrifugarlos (3 $000 \mathrm{rpm}$ ) durante 5 minutos. Los sobrenadantes se vertieron en tubos de dilución, se añadieron $0.4 \mathrm{ml}$ de solución alcohólica de fenol $10 \%$, $0.4 \mathrm{ml}$ de nitroprusiato de sodio al $0.5 \%$ y $1 \mathrm{ml}$ de solución oxidante, reposando por 1 hora. La positividad de la fijación de nitrógeno in vitro se observó mediante una coloración azul la cual se mensuró mediante absorbancia en espectrofotómetro (UV-VIS Genesys ${ }^{\mathrm{TM}}$ 10 Bio, THERMO) a $633 \mathrm{~nm}$. Las concentraciones de nitrógeno fijado como amonio fueron calculadas en una recta patrón obtenida de diluciones sucesivas a partir de una solución madre de 100 ppm de cloruro de amonio (Lara et al., 2007).

Identificación de aislamientos

Los aislamientos bacterianos que tuvieron un potencial como promotores de crecimiento fueron identificados en base a la región $16 \mathrm{~S}$ del ADNr. Para la 
extracción del material genético se siguió el protocolo de Wilson (1997) y se diluyó el ADN extraído en agua estéril Mili-Q antes de continuar con la amplificación. Los fragmentos de la región $16 \mathrm{~S}$ del $\mathrm{ADNr}$ (aproximadamente $1500 \mathrm{pb}$ ) de cada bacteria fueron separados usando los primers universales descritos por Weisburg et al. (1991), fD1 (5, CCGAATTCGTCGACAACAGAGTTTGATCCTGG

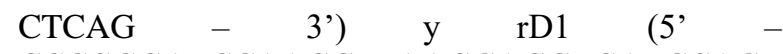
CCCGGGATCCAAGCTTAAGGAGGTGATCCAG

CC - 3'). Las condiciones de reacción fueron: buffer de $\mathrm{PCR}+\left(\mathrm{NH}_{4}\right) 2 \mathrm{SO}_{4}-\mathrm{MgCl}_{2}$ al $1 \mathrm{X}, \mathrm{MgCl}_{2} 1.25 \mathrm{mM}$, mix de nucleótidos $0.2 \mathrm{mM}, 12$ pmoles de cada cebador, $1.25 \mathrm{U}$ Taq polimerasa y $2.4 \mu \mathrm{l}$ de muestra (dilución 1:100); se aplicó el programa: 3 minutos de precalentamiento a $93{ }^{\circ} \mathrm{C}, 30$ ciclos de 45 segundos de desnaturalización a $93{ }^{\circ} \mathrm{C}, 45$ segundos de hibridación del cebador a $62{ }^{\circ} \mathrm{C}, 2$ minutos de elongación $72{ }^{\circ} \mathrm{C}$, y 10 minutos de extensión final a $72{ }^{\circ} \mathrm{C}$. Los productos de la amplificación fueron examinados mediante electroforesis, cargando $5 \mu \mathrm{l}$ del amplificado en gel de agarosa al $1.5 \%$ con buffer de corrida TAE $1 \mathrm{X}$, durante aproximadamente 2 horas a $80 \mathrm{~V}$. Luego, fueron purificados utilizando el GeneJET PCR Purification kit (ThermoScientific, USA) y secuenciados por la empresa MacroGen $($. La comparación de secuencias se realizó en la página web del Centro Internacional de la Información Biológica (NCBI) empleando el algoritmo BLAST (Altschul et al., 1990).

Inoculación en invernadero

El sustrato y el material vegetal se obtuvieron del banco de germoplasma de tarwi del Programa de Cereales y Granos Nativos - UNALM. Las semillas de tarwi fueron desinfectadas con Benomil $1 \mathrm{~g} \cdot \mathrm{l}^{-1}$ y sembradas en sustrato estéril húmedo, mezcla de vermiculita y arena (1:2). A los 15 días, los brotes enraizados fueron trasladados a macetas de $3 \mathrm{~kg}$ con 2.5 $\mathrm{kg}$ de suelo. Luego de cinco días de crecimiento en maceta, se procedió con la inoculación. Para este estudio, se regaron las plantas inoculadas con solución nutritiva (Solución hidropónica La Molina A y B).

Se implementaron cuatro tratamientos para evaluar el efecto de las cepas en el crecimiento de L. mutabilis: un testigo, una co-inoculación y dos inoculaciones individuales. El testigo consistió únicamente en la plántula regada por solución nutritiva, la coinoculación fue una mezcla de la cepa más productora de AIA y la cepa más solubilizadora de fosfato, y las inoculaciones individuales fueron una cepa endofítica y una rizosférica con el mejor resultado simultáneo en las pruebas PGPR, es decir que haya presentado los valores más altos en al menos dos pruebas PGPR. Se agregó a cada maceta $3 \mathrm{ml}$ de inóculo a la concentración de $10^{8} \mathrm{ufc} \cdot \mathrm{ml}^{-1}$. Durante el ensayo se evaluó semanalmente la altura de la planta y a las seis semanas, se evaluó peso fresco y seco de la parte aérea y radicular de la planta.
Para el análisis, se utilizó el Diseño Completo al Azar (DCA) con cuatro tratamientos y 10 repeticiones. Los datos fueron analizados utilizando el análisis de varianza ANOVA y la prueba comparativa Diferencia Mínima Significativa $(\mathrm{P} \leq 0.05)$ empleando el software estadístico R.

\section{Resultados y discusión \\ Aislamiento de microorganismos}

Se obtuvieron en total 333 cultivos puros, de los cuales 190 eran de bacterias y 143 de hongos (Figura 1). La mayoría de los aislados provenían de la rizósfera $(80.8 \%, 269)$, sólo un $19.2 \%$ (64) eran potenciales endófitos de tarwi porque fueron encontrados dentro de tallos, raíces y nódulos. Al ser la rizósfera una zona de interacción con la planta, los microorganismos encuentran en ella un ambiente favorable con nutrientes orgánicos provenientes de las raíces, y esto conlleva a que la concentración de microorganismos en la rizósfera generalmente sea mucho mayor que en el resto del suelo (Glick, 1995). Este resultado es comparable con estudios como el de Angulo et al. (2014) y Ayubb et al. (2017), quienes también obtuvieron mayor cantidad de aislados rizosféricos que de endófitos a partir de Eucalyptus nitens y Oriza sativa, respectivamente.

Por otro lado, los factores ambientales y edáficos influyen sobre la presencia y distribución de microorganismos en el suelo (Dick, 1992). La actividad microbiana está fuertemente determinada por el potencial hídrico, cuando éste alcanza valores muy negativos la actividad microbiana cesa (Jenkinson, 1992); la estructura, porosidad, $\mathrm{pH}$ y potencial redox, son factores que en su conjunto actúan de un modo u otro para influir sobre la densidad y actividad microbiana (IGAC, 1993); e incluso las prácticas de cultivo o la edad de la planta ejercen efectos sobre las poblaciones microbiales. En este proyecto, el $64.6 \%$ (215) de los aislamientos pertenecía al IRD-Sierra, en Jauja, por lo cual se podría inferir que las condiciones ambientales y edáficas presentes en los campos de Jauja fueron más favorables para la presencia de microorganismos, pero esto requiere un estudio a profundidad para poder confirmarlo.

\section{HONGOS}

Antagonismo frente a un patógeno e identificación de cepas

De un total de 143 aislados, sólo 9 inhibieron el crecimiento de Fusarium oxysporum. Los porcentajes de inhibición de estas nueve cepas se observan en la Tabla 1.

Estas cepas antagonistas fueron las únicas que continuaron con el proceso de identificación a nivel de género mediante microscopía. Así se observó que cinco de ellas pertenecían al género Aspergillus, dos a Penicillium y las dos restantes no pudieron ser identificadas por falta de estructuras vegetativas observables. Para cada género, se identificaron hasta 
nivel de especie las cepas más antagonistas (Tabla 1, Figura 2): $\mathrm{N}^{\circ} 134$ para Aspergillus y $\mathrm{N}^{\circ} 96$ para Penicillium.

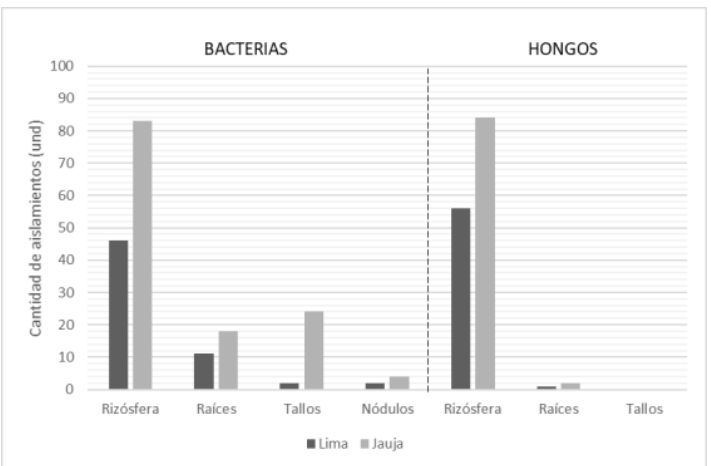

Figura 1. Cantidad de cepas aisladas a partir de las muestras de Lupinus mutabilis.

Tabla 1. Porcentaje de inhibición de Fusarium oxysporum por las cepas fúngicas.

\begin{tabular}{|c|c|c|}
\hline $\begin{array}{l}\mathbf{N}^{\circ} \\
\text { Cepa }\end{array}$ & 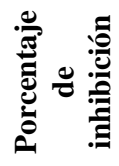 & Género más cercano \\
\hline 40 & 60.0 & No identificado \\
\hline 43 & 57.1 & No identificado \\
\hline 47 & 46.1 & Aspergillus sp. \\
\hline 96 & 64.0 & Penicillium citrinum \\
\hline 99 & 61.0 & Penicillium sp. \\
\hline 103 & 57.1 & Aspergillus sp. \\
\hline 105 & 38.5 & Aspergillus sp. \\
\hline 131 & 70.0 & Aspergillus sp. \\
\hline 134 & 74.0 & Aspergillus terreus \\
\hline
\end{tabular}

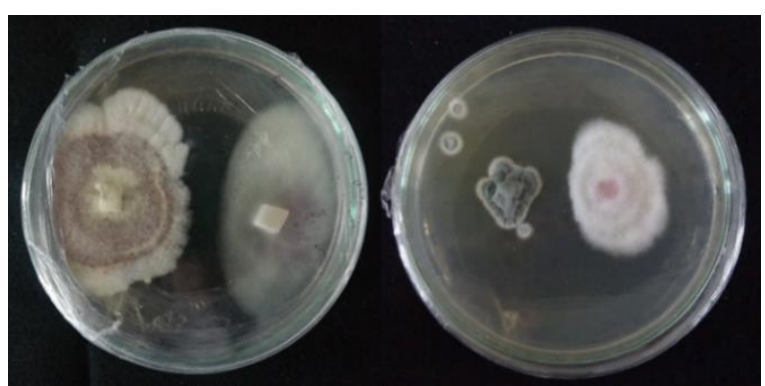

Figura 2. Aspergillus (Izquierda) y Penicillium (Derecha) en interacción dual con Fusarium oxysporum.

Las características macro y microscópicas de la cepa $\mathrm{N}^{\circ} 134$ se muestran en la Figura 3. Se observa que esta cepa es de textura aterciopelada-arenosa, es de color marrón en el centro y blanco en los bordes cuando es joven, pero totalmente marrón cuando crece. Llega a medir $4 \mathrm{~cm}$ de diámetro a los seis días de incubación en agar OGY y presenta un ligero pigmento amarillo en el medio. A $100 \mathrm{X}$, se observan un conidióforo con vesícula globosa y cabeza conidial en forma de abanico levemente columnar, conidios globosos, ausencia de ascas y ascosporas. Estas características concuerdan con un estudio de hongos filamentosos en suelo de páramo (Arias \& Piñeros, 2008), donde se describen a las colonias de Aspergillusterreus como aterciopeladas, de color rosado parduzco que alcanzan un diámetro de $3.5-5 \mathrm{~cm}$ en 7 días, con exudado incoloro y producción de un pigmento amarillo difusible en el medio. Además, comparando nuestros datos con las claves taxonómicas descritas por Gómez (1951) y Piontelli (2008), se puede afirmar que la cepa $\mathrm{N}^{\mathrm{o}} 134$ es identificada como Aspergillus terreus.
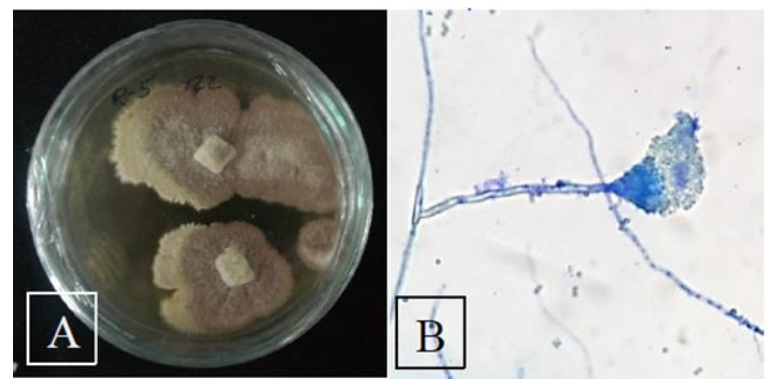

Figura 3. Colonia de cepa $\mathrm{N}^{\circ} 134$ en medio OGY (Izquierda) y estructura vegetativa observada a $100 \mathrm{X}$ (Derecha).

Las características macro y microscópicas de la cepa $\mathrm{N}^{\circ} 96$ se muestran en la Figura 4. Se observan colonias puntiformes de textura aterciopelada, color verde con bordes blancos. A $100 \mathrm{X}$ e observaron conidios redondos, unicelulares formando cadenas no ramificadas. Para poder identificarla hasta nivel de especie, esta cepa fue analizada en el departamento de Fitopatología de la UNALM, determinándose que se trataba de la especie Penicillium citrinum.
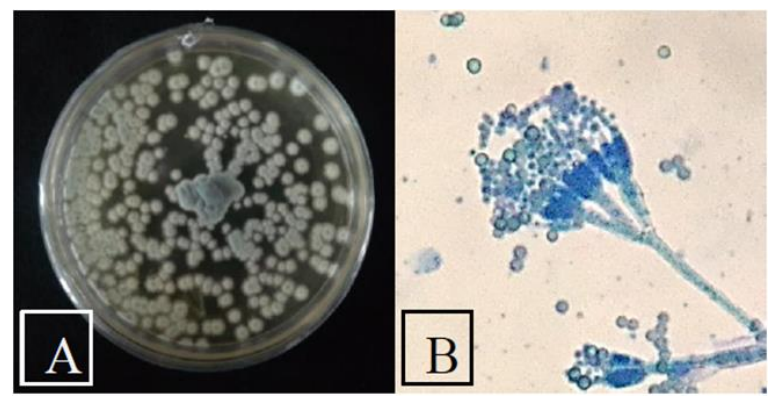

Figura 4. Colonia de cepa $\mathrm{N}^{\circ} 96$ en medio OGY (Izquierda) y estructura vegetativa observada a $100 \mathrm{X}$ (Derecha).

Aspergillus terreus ha sido encontrado como antagonista de Fusarium oxysporum en estudios anteriores: Dawood \& Mohamed (2015) estudiaron tres aislamientos de A. terreus como control biológico, los cuales inhibieron hasta un $89 \%$ el crecimiento de $F$. oxysporum por interacción dual; Bashar \& Chakma (2014) evaluaron colonias de A. terreus que inhibieron a $F$. oxysporum mediante interacción dual y producción 
de metabolitos no volátiles en un $53.33 \%$ y $83.33 \%$, respectivamente. Estos trabajos respaldan lo encontrado en nuestra cepa de A. terreus, pues llegó a inhibir el crecimiento del patógeno en $74 \%$, valor similar a lo descrito anteriormente. Quiroz et al. (2008) indica que Aspergillus muestra mecanismos antagónicos de competencia por espacio y producción de sustancias antibióticas denotadas por el cambio de coloración en el medio. Se puede inferir que A. terreus presenta estos dos tipos de acción frente al patógeno.

Penicillium citrinum ha sido catalogado como un patógeno indefinido, es decir, un microorganismo que, sin ser considerado normalmente como fitopatógeno, puede llegar a inhibir el crecimiento de la planta (Hyakumachi \& Kubota, 2004). Sin embargo, científicos han evaluado también la capacidad antagónica de este hongo. Alwathnani et al. (2012), evaluaron el potencial de control biológico de algunos antagonistas locales frente a $F$. oxysporum f. sp. phaseoli y sus resultados del ensayo in vitro revelaron que $P$. citrinum inhibió el crecimiento del patógeno en un $59 \%$. Junto a otras pruebas, concluyen que este hongo tiene gran potencial de ser usado como agente de control biológico. Dwivedi \& Enespa (2013) obtuvieron también resultados similares, a través de la técnica "poisoned food" observaron que $P$. citrinum inhibió el crecimiento de $F$. oxysporum f. sp. lycopersici en un $67.54 \%$. Estos resultados respaldan lo observado en nuestro estudio: la inhibición del patógeno en un $64 \%$ por parte de $P$. citrinum.

Es importante conocer que los hongos que presentan actividad antagonista in vitro, pueden no mostrar resultados similares in situ debido a las condiciones ambientales y la competencia con otros microorganismos (Alwathnani et al., 2012).

\section{BACTERIAS}

Capacidades de promoción de crecimiento vegetal e identificación de cepas

La prueba de producción de AIA fue un tamizaje para reducir los 184 aislamientos obtenidos de raíces, tallos y rizósfera. Fueron seleccionados 36, por mostrar resultados positivos en la producción de indol y con estas cepas se realizaron las siguientes pruebas PGPR donde: 8 mostraron capacidad para solubilizar fosfatos tricálcicos, 10 mostraron capacidad antagónica contra Fusarium oxysporum y 35 produjeron sideróforos. Se descartaron aquellas cepas que no solubilizaron fosfato tricálcico ni mostraron antagonismo contra el patógeno y cuya producción de sideróforos (ERP) fue menor a 2. La fijación in vitro de nitrógeno se realizó sólo en las 6 cepas provenientes de nódulos y todas resultaron positivas, con una fijación en el rango de $4.6-8.5 \mathrm{mg} / 1$ $\mathrm{NH}_{4}{ }^{+}$. En la Tabla 2, se observan los resultados de las pruebas PGPR de estos aislamientos.

La identificación molecular se realizó en aquellos aislados que presentaron la producción de AIA y solubilización de fosfatos simultáneamente (8 aislados), y a todas las cepas de nódulos (6 aislados). El análisis comparativo de las secuencias de la región 16S del ADNr obtenidas con aquellas registradas en la base de datos de NCBI mostró que de los 14 aislados, 9 pertenecían al género Bacillus, 2 al género Lysinibacillus, 1 al género Paenibacillus, 1 al género Enterococcus y 1 al género Achromobacter (Tabla 3).

Tabla 3. Identificación molecular de aislados bacterianos.

\begin{tabular}{|c|c|c|c|}
\hline 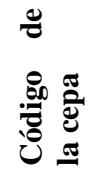 & Especie más cercana & Accesión & 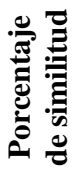 \\
\hline RB01 & $\begin{array}{l}\text { Achromobacte marplatensis } \\
\text { CCUG } 56371\end{array}$ & NR_118400.1 & 99 \\
\hline RB02 & $\begin{array}{l}\text { Bacillus toyonensis } \\
\text { BCT } 7112\end{array}$ & NR_121761.1 & 99 \\
\hline RB08 & $\begin{array}{l}\text { Lysinibacillus macroides } \\
\text { LMG } 18474\end{array}$ & NR_114920.1 & 99 \\
\hline RB10 & $\begin{array}{l}\text { Bacillus circulans } \\
\text { NBRC } 13626\end{array}$ & NR_112632.1 & 96 \\
\hline RB14 & $\begin{array}{l}\text { Bacillus cereus } \\
\text { ATCC } 14579\end{array}$ & NR_074540.1 & 99 \\
\hline RB22 & $\begin{array}{l}\text { Paenibacillus polymyxa } \\
\text { IAM } 13419\end{array}$ & NR_112117.1 & 99 \\
\hline ТВ01 & $\begin{array}{l}\text { Enterococcus mundtii } \\
\text { NBRC } 100490\end{array}$ & NR_113906.1 & 98 \\
\hline TB05 & $\begin{array}{l}\text { Lysinibacillus macroides } \\
\text { LMG } 18474\end{array}$ & NR_114920.1 & 100 \\
\hline NR01 & $\begin{array}{l}\text { Bacillus cereus } \\
\text { ATCC } 14579\end{array}$ & NR 074540.1 & 100 \\
\hline NR02 & $\begin{array}{l}\text { Bacillus pumilus } \\
\text { NBRC } 12092\end{array}$ & NR 112637.1 & 98 \\
\hline NR03 & $\begin{array}{l}\text { Bacillus aryabhattai } \\
\text { B8W22 }\end{array}$ & NR 118442.1 & 98 \\
\hline NR04 & $\begin{array}{l}\text { Bacillus licheniformis } \\
\text { DSM } 13\end{array}$ & NR_118996.1 & 99 \\
\hline NR05 & $\begin{array}{l}\text { Bacillus pumilus } \\
\text { NBRC } 12092\end{array}$ & NR_112637.1 & 99 \\
\hline NR06 & $\begin{array}{l}\text { Bacillus licheniformis } \\
\text { DSM } 13\end{array}$ & NR_118996.1 & 95 \\
\hline
\end{tabular}

La producción de ácido indol acético y sus beneficios en la promoción de crecimiento vegetal ha sido ampliamente reportada. Esta auxina es producida no sólo por plantas superiores, sino también por bacterias y hongos, lo cual posee un rol significativo en la interacción planta-microorganismo pues contribuye en la promoción del crecimiento radicular y foliar de la planta (Vega-Celedón et al., 2016). La solubilización de fosfatos y producción de sideróforos juegan también un rol importante en esta interacción porque hacen disponibles a los nutrientes poco solubles, aumentando la disponibilidad de éstos para que las plantas puedan asimilarlos. La cepa RB10 (Bacillus circulans) mostró la más alta capacidad solubilizadora de fosfato (Figura 5), logrando un 4.96 de eficiencia relativa de solubilización, es decir que la bacteria solubilizó cinco veces más que su crecimiento de colonia. Este valor fue superior a lo reportado por Ortiz (2013) en un estudio 
de bacterias aisladas de rizósfera de Lepidium meyenii (maca), donde se obtuvo una ERS máxima de 1.28 y en un estudio de rizobacterias de Phaseolus vulgaris (frijol), donde el máximo diámetro de solubilización fue $1 \mathrm{~cm}$ (Vúlchez, 2017), en comparación a los $2.88 \mathrm{~cm}$ que alcanzó RB10. Bacillus circulans, como tal, es reportado también en un estudio de rizósfera de manzana donde mostró capacidades de solubilización de fosfato, producción de AIA, actividad de ACC desaminasa, actividad nitrogenasa, producción de sideróforos, entre otros (Mehta et al., 2015). El aislado RB11 fue el más antagonista frente a Fusarium oxysporum (Figura 5), pero logró sólo un $49.37 \%$ de inhibición, valor inferior a estudios de bacterias rizosféricas que lograron un $100 \%$ y $96 \%$ frente a Fusarium oxysporum en arroz (Trujillo et al., 2007) y vainilla (Adame et al., 2009), respectivamente. El aislado RB08 (Lysinibacillus macroides) fue el que produjo mayor cantidad de sideróforos (Figura 5), alcanzando un 5.00 de eficiencia relativa de producción y un halo de $4 \mathrm{~cm}$, valor superior a lo reportado en un estudio de cepas de Azospirillum en frutilla, donde obtuvieron un máximo diámetro de producción de 2.38 cm (Tortora et al., 2007) y en un estudio bacterias PGPR en tomate, donde el máximo diámetro fue $1.7 \mathrm{~cm}$ (Sánchez, 2011). La fijación de nitrógeno más alta se observó para la cepa NR05 (Bacillus pumilus), con una concentración de $6 \mathrm{mg} \cdot \mathrm{l}^{-1}$ de ion amonio, valor relativamente mayor al reportado para Azotobacter y Azospirillum - dos géneros comúnmente conocidos como fijadores de nitrógeno - que obtuvieron 5.2 y 4.6 mg. ${ }^{-1}$, respectivamente (Lara et al., 2007). La capacidad fijadora de Bacillus pumilus se demostró en un estudio en Eleusine coracana (Dheeman et al., 2019) donde se observó que esta bacteria tuvo un buen crecimiento hasta siete generaciones después en un medio Ashby libre de nitrógeno, lo que significa que utilizó nitrógeno atmosférico como fuente de nitrógeno para crecer.

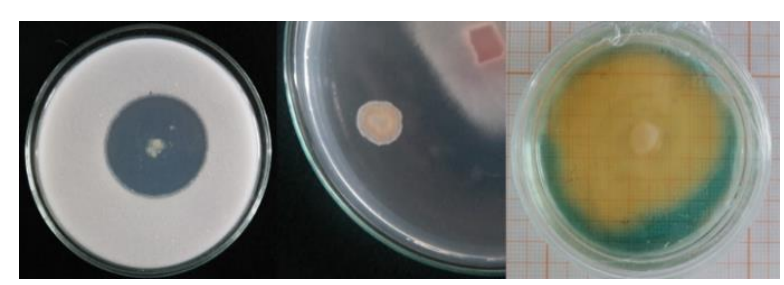

Figura 5. Cepa más solubilizadora de fosfato tricálcico, RB10 (Izquierda); cepa más antagonista de Fusarium oxysporum, RB11 (Centro); y cepa más productora de sideróforos, RB08 (Derecha).

Los géneros encontrados en esta investigación han sido reportados con anterioridad en trabajos como el de Liceta (2015) en sus aislamientos de rizósfera de quinua y por Barquero (2014) en sus aislados de raíces de alubia y pimiento. Especies de Paenibacillus fueron encontradas asociadas a rizósfera de diferentes cultivos (Coelho et al., 2008), Calvo \& Zuñiga (2010) aislaron especies de Bacillus en rizósfera de papa y Oliva (2015) logró aislar especies de Bacillus en rizósfera de Lupinus mutabilis para demostrar su potencial como controlador biológico. En nuestros resultados se observó que cepas rizosféricas y endofíticas tuvieron la misma identificación en especie, tal es el caso de RB08 y TB05, identificadas como Lysinibacillus macroides, y RB14 con TB01, identificadas como Bacillus cereus. Esto puede ser debido a que la rizósfera - uno de los ecosistemas más diversos - se ha propuesto como una fuente de adquisición de endófitos para las plantas, ya que las grietas en los tejidos de la planta permiten a las bacterias rizosféricas penetrar y colonizar tejidos internos (Sørensen \& Sessitsch, 2007). En este trabajo, todas las cepas aisladas de nódulos se identificaron como Bacillus, la presencia de este género en nódulos se debe a que generalmente Bacillus y Paenibacillus son endofíticos de nódulos (Costa et al., 2013). Por otro lado, si bien el género Bacillus no es reconocido como una bacteria que nodula, sino más como una endofítica de nódulos, algunos trabajos han verificado nodulación para estos géneros (Marra et al., 2012; Jaramillo et al., 2013).

La evaluación de las capacidades PGPR en esta investigación, medidas cualitativamente, nos permitió encontrar microorganismos con potencial uso como bioestimuladores, sin embargo, se necesitan más pruebas in vitro y en campo, para determinar realmente su efectividad.

Inoculación en plántulas de tarwi a nivel de invernadero

La selección de los inoculantes se realizó a partir de los 23 aislados descritos en la Tabla 2. La cepa con mayor producción de AIA fue RB14 y la más solubilizadora de fosfato fue RB10, ambos formaron parte de la co-inoculación. El tercer tratamiento fue RB01 por ser la cepa rizosférica con los valores más altos en solubilización de fosfato y producción de AIA, simultáneamente. Por último, el cuarto tratamiento fue TB05, como la cepa endofítica con más alto valor en solubilización de fosfatos y producción de sideróforos. Las variables evaluadas fueron altura de planta (Tabla $4)$, longitud de inflorescencia (Tabla 5), peso fresco y seco (Tabla 6).

En la evaluación realizada a los 42 días $(\mathrm{p}=0.096)$, aunque no se observaron diferencias significativas en altura de planta, TB05 mostró valores más altos en comparación a los otros tratamientos, siendo un $11 \%$ superior al control. El tamaño de la inflorescencia en las plántulas también fue evaluado en dos ocasiones. A los 24 días $(\mathrm{p}=0.218)$ se observó que los tratamientos mostraron inflorescencias de mayor longitud que el control, pero sólo TB05 logró valores superiores con un promedio de $19.1 \mathrm{~mm}$ en comparación al testigo quien obtuvo un promedio de $13.7 \mathrm{~mm}$. A los 35 días ( $\mathrm{p}=$ 0.334), el inóculo mixto (RB10/14) logró el mayor promedio de longitud $(61.8 \mathrm{~mm})$, sin embargo, ninguno de los tratamientos mostró significancia estadística respecto al control, cuyo valor promedio de longitud fue $41.7 \mathrm{~mm}$. 
Tabla 4. Evaluación de altura $(\mathrm{cm})$ en plántulas de tarwi. Datos por tratamiento de inoculación.

\begin{tabular}{lllllll}
\hline DDI & $\mathbf{0}$ & $\mathbf{1 0}$ & $\mathbf{1 7}$ & $\mathbf{2 4}$ & $\mathbf{3 5}$ & $\mathbf{4 2}$ \\
\hline Testigo & $16.55 \pm 1.96 \mathrm{a}$ & $26.89 \pm 2.38 \mathrm{a}$ & $34.89 \pm 2.60 \mathrm{~d}$ & $50.56 \pm 5.44 \mathrm{~b}$ & $69.89 \pm 6.92 \mathrm{~b}$ & $75.44 \pm 6.98 \mathrm{~b}$ \\
RB10/14 & $16.20 \pm 2.04 \mathrm{a}$ & $27.10 \pm 2.56 \mathrm{a}$ & $37.22 \pm 1.75 \mathrm{c}$ & $52.56 \pm 5.48 \mathrm{ab}$ & $78.33 \pm 7.97 \mathrm{a}$ & $82.33 \pm 8.59 \mathrm{ab}$ \\
RB01 & $17.10 \pm 1.52 \mathrm{a}$ & $28.30 \pm 2.06 \mathrm{a}$ & $39.40 \pm 1.43 \mathrm{~b}$ & $54.40 \pm 3.63 \mathrm{ab}$ & $74.00 \pm 7.01 \mathrm{ab}$ & $77.70 \pm 6.89 \mathrm{ab}$ \\
TB05 & $17.45 \pm 3.87 \mathrm{a}$ & $28.60 \pm 4.11 \mathrm{a}$ & $41.22 \pm 1.62 \mathrm{a}$ & $56.22 \pm 4.89 \mathrm{a}$ & $77.22 \pm 5.47 \mathrm{a}$ & $83.22 \pm 8.52 \mathrm{a}$ \\
\hline
\end{tabular}

DDI: Días después de la inoculación.

abcd: Comparación mediante la prueba de Diferencia Mínima Significativa, por columna.

Tabla 5. Evaluación de inflorescencia (mm) en plántulas de tarwi. Datos por tratamiento de inoculación.

\begin{tabular}{lll}
\hline DDI & $\mathbf{2 4}$ & $\mathbf{3 5}$ \\
\hline Testigo & $13.75 \pm 5.74 \mathrm{~b}$ & $41.77 \pm 22.70 \mathrm{a}$ \\
RB10/14 & $17.26 \pm 5.07 \mathrm{ab}$ & $61.68 \pm 19.86 \mathrm{a}$ \\
RB01 & $15.46 \pm 4.17 \mathrm{ab}$ & $58.11 \pm 31.69 \mathrm{a}$ \\
TB05 & $19.15 \pm 6.98 \mathrm{a}$ & $53.49 \pm 19.68 \mathrm{a}$ \\
\hline DDI: Días después de la inoculación. \\
abcd: Comparación mediante la prueba de Diferencia \\
\multicolumn{2}{l}{ Mínima Significativa, por columna. }
\end{tabular}

Tabla 6. Evaluación de peso fresco y seco $(\mathrm{g})$ en plántulas de tarwi a los 42 DDI. Datos por tratamiento de inoculación.

\begin{tabular}{lll}
\hline & Peso fresco $(\mathbf{g})$ & Peso seco $(\mathbf{g})$ \\
\hline Testigo & $40.45 \pm 14.09 \mathrm{a}$ & $6.28 \pm 2.34 \mathrm{a}$ \\
$\mathrm{RB} 10 / 14$ & $40.25 \pm 13.98 \mathrm{a}$ & $6.41 \pm 2.41 \mathrm{a}$ \\
$\mathrm{RB} 01$ & $39.88 \pm 15.85 \mathrm{a}$ & $6.85 \pm 2.33 \mathrm{a}$ \\
TB05 & $51.52 \pm 8.28 \mathrm{a}$ & $8.15 \pm 1.60 \mathrm{a}$ \\
\hline \multicolumn{2}{l}{ abcd: Comparación mediante la prueba de Diferencia } \\
\multicolumn{2}{l}{ Mínima Significativa, por columna. }
\end{tabular}

Al finalizar el ensayo en invernadero, se evaluó el peso fresco y seco de las plántulas de tarwi. En ambos casos, el inóculo TB05 mostró los mayores valores, sin embargo, no se encontró significancia entre los promedios con respecto al control $(\mathrm{p}=0.204$ para peso fresco y $\mathrm{p}=0.275$ para peso seco). Se puede resaltar, además, que sólo para el parámetro peso seco, los otros tratamientos mostraron también valores superiores al control. El tratamiento TB05 fue el único que formó frutos (dato no evaluado por ausencia de resultados en los otros tratamientos), y fue un aislado endófito proveniente de los tallos de Lupinus mutabilis. Al respecto, Rosenblueth \& Martínez (2006) indican que la capacidad de las bacterias de colonizar tejidos internos de las plantas puede conferirles una ventaja ecológica sobre las bacterias rizosféricas, pues pueden protegerse mejor de los factores bióticos y tensiones abióticas que condicionan a todas las poblaciones bacterianas. Dibut et al. (2009) nos mencionan distintos estudios en Cuba con inoculación del endófito Gluconacetobacter diazotrophicus en cultivos de importancia económica; por ejemplo, en Ipomoea batatas (camote) se logró incrementar el largo de las plantas en un $34 \%$, el número de hojas en un $62 \%$, diámetro del tallo en un $40 \%$, diámetro del tubérculo en un $45 \%$ en relación con plantas testigo; en Colocasia esculenta (malanga) se incrementó el rendimiento agrícola en un 38\%; en Manihot esculenta (yuca) se incrementó la altura en un $36 \%$, entre otros. Los porcentajes de incremento de la cepa TB05 respecto al control son $10 \%$ para la altura de planta, $28 \%$ para el tamaño de inflorescencia, $27 \%$ para peso fresco y $29 \%$ para peso seco, que si bien, no tuvieron significancia estadística, sugiere a TB05 como un tratamiento con potencial a ser utilizado como bioinoculante.

\section{Conclusiones}

En este estudio se aislaron bacterias y hongos rizosféricos y endofíticos, los cuales mostraron mecanismos de acción para la promoción de crecimiento de la planta. La mayor parte de los aislamientos bacterianos se identificaron pertenecientes a la familia Bacillaceae. Los géneros encontrados fueron Bacillus, Achromobacter, Lysinibacillus, Paenibacillus y Enterococcus, para bacterias y Aspergillus y Penicillium para hongos. La bacteria endofítica TB05 identificada como Lysinibacillus macroides incrementó en un $10 \%$ la altura en plántulas de tarwi en invernadero. Los resultados observados nos permiten sugerir el potencial de uso de estos microorganismos como biofertilizantes para este cultivo. Las evaluaciones futuras in vivo deben apuntar a confirmar el potencial uso de estas cepas como inoculantes, biofertilizantes o agentes de control biológico para reemplazar productos químicos e incrementar la sostenibilidad en la agricultura.

\section{Agradecimientos}

A la oficina de investigación de la Universidad Nacional Agraria La Molina por el financiamiento otorgado y al Programa de Cereales y Granos Nativos Facultad de Agronomía de la misma universidad por las facilidades para realizar los muestreos y los ensayos. Al Magister Roger Torres Aliaga por su colaboración en la caracterización molecular de este estudio.

\section{Literatura citada}

Adame J., Luna M. \& Trigos A.R. 2009. Bacterias antagonistas de hongos fitopatógenos asociadas a la raíz de Vanilla planifolia Andrews. Agricultura sostenible, 6: 29-35. 
Altschul S., Gish W., Miller W., Myers W. \& Lipman D. 1990. Basic local alignment search tool. J. Mol. Biol., 215(3): 403-410. DOI: https://doi.org/10.1016/S00222836(05)80360-2.

Alwathnani H.A., Perveen K., Tahmaz R. \& Alhaqbani S. 2012. Evaluation of biological control potential of locally isolated antagonist fungi against Fusarium oxysporum under in vitro and pot conditions. African Journal of Microbiology Research, 6(2): 312-319. https://academicjournals.org/journal/AJMR/articleabstract/35C1F7218222.

Angulo V., Sanfuentes E., Rodríguez F. \& Sossa K. 2014. Caracterización de rizobacterias promotoras de crecimiento en plántulas de Eucalyptus nitens. Revista Argentina de Microbiología, 46(4): 338-347. DOI: https://doi.org/10.1016/S0325-7541(14)70093-8.

Arias E.D. \& Piñeros P.A. 2008. Aislamiento e Identificación de hongos filamentosos de muestras de suelo de los páramos de guasca y cruz verde. Tesis Lic. Pontificia Universidad Javeriana. Bogotá D.C.

Ayubb T.N., Cerra G.A., Chamorro A.L. \& Pérez C.A. 2017. Resistencia a cadmio (Cd) de bacterias endófitas y bacterias rizosféricas aisladas a partir de Oriza sativa en Colombia. Revista Colombiana de Ciencia Animal RECIA, 9(2): 281. https://doi.org/10.24188/recia.v9.n2.2017.610.

Baldomero O. 2015. El Tarwi. Alternativa para la lucha contra la desnutrición infantil. Serie Manual Nro 1. MINAGRI / INIA http://repositorio.inia.gob.pe/handle/inia/731.

Barquero M. 2014. Caracterización y selección de bacterias y hongos micorrícicos aislados en raíces de alubia y pimiento, en la provincia de León, para el desarrollo de biofertilizantes. Tesis Ph. D. Universidad de Salamanca. http://hdl.handle.net/10366/127303.

Bashar M.A. \& Chakma M. 2014. In vitro control of Fusarium solani and Fusarium oxysporum the causative agent of brinjal wilt. Journal of Biological Sciences, 23(1): 53-60. DOI: https://doi.org/10.3329/dujbs.v23i1.19826.

Calvo P. \& Zuñiga D. 2010. Caracterización fisiológica de cepas de Bacillus spp. aisladas de la rizósfera de papa (Solanum tuberosum). Ecología Aplicada, 9(1): 32-39. DOI: http://dx.doi.org/10.21704/rea.v9i1-2.393.

Canahua A. \& Roman P. 2016. Tarwi. Leguminosa andina de gran potencial. LEISA Revista de Agroecología, 32(2): 20-21. http://www.leisa-al.org/web/index.php/volumen32-numero-2/1513-tarwi-leguminosa-andina-de-granpotencial.

Carro L., Flores J.D., Ramírez M.H., García P., Martínez P., Igual J.M., Tejedor C., Peix A. \& Velázquez E. 2014. Paenibacillus lupini sp. nov. isolated from nodules of Lupinus albus. International Journal of Systematic and Evolutionary Microbiology, (64): 3028-3033. DOI: 10.1099/ijs.0.060830-0.

Carvajal-Larenas F.E., Linnemann A.R., Nout M.J.R., Koziol M. \& Van Boekel M.A.J.S. 2016. Lupinus mutabilis: Composition, Uses, Toxicology and Debittering. Critical Review in Food Science and Nutrition, 56(9): 1454-1487. DOI: https://doi.org/10.1080/10408398.2013.772089.
Claros M. \& Ortuño N. 2013. Aislamiento y caracterización funcional de bacterias endófitas en el cultivo de la quinua (Chenopodium quinoa Wild.). En: Vargas M. (Ed) Congreso Científico de la Quinua (Memorias), La Paz, Bolivia, 14 y 15 de junio de 2013. IICA. https://repositorio.iica.int/bitstream/handle/11324/2562/ BVE17038657e.pdf;jsessionid=8B90CAAC2BDA4662 3000DE45A917F280? sequence $=1$.

Clavijo C., Chipana V., Centeno J., Zúñiga D. \& Guillén C. 2012. Aislamiento, caracterización e identificación de bacterias diazotróficas de la rizósfera del cultivo de Olea europea "Olivo" en Tacna-Perú. Ecología Aplicada, 11(2): $\quad$ 89-102. DOI: http://dx.doi.org/10.21704/rea.v11i1-2.429.

Coelho M.R., De Vos M., Carneiro N.P., Marriel I.E., Paiva E. \& Seldin L. 2008. Diversity of the nifH genes pools in the rizosphere of two cultivars of sorghum (Sorghum bicolor) treated with contrasting level of nitrogen fertilizer. FEMS Microbiol. Lett., 279(1): 15-22. DOI: https://doi.org/10.1111/j.1574-6968.2007.00975.x.

Costa E.M., Abrahão R.S., de Carvalho F., Trochmann A., Martins L. \& de Souza F.M. 2013. Promoção do crescimento vegetal e diversidade genética de bactérias isoladas de nódulos de feijão-caupi. Pesquisa Agropecuária Brasileira, 48(9): 1275-1284. DOI: http://dx.doi.org/10.1590/S0100-204X2013000900012.

Dawood E.S. \& Mohamed A.A. 2015. Isolation and screening of different chitinolytic mycoflora isolated from sudanese soil for biological control of Fusarium oxysporum. Asian Journal of Agriculture and food sciences, 3(4): 412-418. https://ajouronline.com/index.php/AJAFS/article/view/2 992.

De Meyer S.E. \& Willens A. 2012. Multilocus sequence analysis of Bosea species and description of Bosea lupini sp. nov., Bosea lathyri sp. nov. and Bosea robiniae sp. nov., isolated from legumes. International Journal of Systematic and Evolutionary Microbiology, 62(10): 2505-2510. DOI: https://doi.org/10.1099/ijs.0.035477-0.

Dheeman S., Baliyan N., Dubey R.C., Maheshwari D.K., Kumar S. \& Chen L. 2019. Combined effects of Rhizocompetitive Rhizosphere and Non-rhizosphere Bacillus in Plant Growth Promotion and Yield Improvement of Eleusine coracana (Ragi). Canadian Journal of Microbiology, 66(2): 111-124. DOI: https://doi.org/10.1139/cjm-2019-0103.

Dibut B., Martínez R., Ortega M., Ríos Y., Tejeda G., Planas L. \& Rodríguez J. 2009. Situación actual y perspectiva de las relaciones endófitas planta-bacteria. Estudio de caso Gluconacetobacter diazotrophicus - Cultivos de importancia económica. Cultivos Tropicales, 30(4): 1623.

http://ediciones.inca.edu.cu/index.php/ediciones/article/d ownload/769/pdf. https://www.redalyc.org/articulo.oa?id=193221673003.

Dick R.P. 1992. A review: long-term effects of agricultural systems on soil biochemical and microbial parameters. Agric. Ecosyst. Environ., 40: 25-36. DOI: https://doi.org/10.1016/0167-8809(92)90081-L. 
Dwivedi S.K. \& Enespa S. 2013. In vitro efficacy of some fungal antagonists against Fusarium solani and Fusarium oxysporum f.sp. lycopersici causing brinjal and tomato wilt. International journal of Biological \& Pharmaceutical Research, 4(1): 46-52. http://www.ijbpr.com/showpdf/MjAza2FsYWkxNDc4N TIzNjk=.

Eastwood R.J., Drummond C.S., Schifino-Wittmann M.T. \& Hughes C.E. 2008. Diversity and evolutionary history of Lupins-insights new phylogenies. In: Berger J.B. \& Palta J.A. (Eds.) Lupins for Health and Wealth. Proceedings of the 12th International Lupin Conference 14-18 Sept. 2008, Fremantle, Western Australia. International Lupin Association. Canterbury, New Zealand.

Fernández R.J. \& Suárez C.L. 2009. Antagonismo in vitro de Trichoderma harzianum Rifai sobre Fusarium oxysporum Schlecht f.sp. passiflorae en maracuyá (Passiflora edulis Sims var. Flavicarpa) del municipio zona bananera colombiana. Revista Facultad Nacional de Agronomía-Medellín, 62(1): 4743-4748. https://revistas.unal.edu.co/index.php/refame/article/vie w/24872.

Flores-Félix J.D., Carro L., Ramírez-Bahena M.H., Tejedor C., Igual J.M., Peix A. \& Velázquez E. 2014. Cohnella lupini sp. nov., an endophytic bacterium isolated from root nodules of Lupinus albus. International Journal of Systematic and Evolutionary Microbiology, 64(1): 83-87. DOI: https://doi.org/10.1099/ijs.0.0508490 .

Glick B.R. 1995. The enhancement of plant growth by freeliving bacteria. Canadian Journal of Microbiology, 41(2): 109-117. DOI: https://doi.org/10.1139/m95-015.

Gómez J.L. 1951. Clave determinativa de las especies del género Aspergillus. Universidad de Murcia. http://hdl.handle.net/10201/6483.

Gordon S.A. \& Weber R.P. 1950. Colorimetric estimation of Indoleacetic acid. Plant Physiology, 26(1): 192-195. DOI: https://dx.doi.org/10.1104\%2Fpp.26.1.192.

Hyakumachi M. \& Kubota M. 2004. Fungi as plant growth promoter and disease suppressor. Adora D.K. (ed.) Fungal Biotechnology in Agricultural, Food and Environmental Applications, 101-110.

IGAC (Instituto Geográfico Agustín Codazzi). 1993. Aspectos ambientales para el ordenamiento territorial del occidente del departamento de Caquetá: capítulos I-II-III. INPA-IGAC. Bogotá.

Jacobsen S.E. \& Mujica A. 2006. El Tarwi (Lupinus mutabilis Sweet) y sus parientes silvestres. En: Moraes M., Øllgaard B., Peter L., Borchsenius F. \& Balslev H. (eds) Botánica Económica de los Andes Centrales, 458-482. Universidad Mayor de San Andrés. https://www.academia.edu/31617453/Bot\%C3\%A1nica _Econ\%C3\%B3mica_de_los_Andes_Centrales_2006_p df.

Jaramillo P.M.D., Guimarães A.A., Florentino L.A., Barroso K., Abrahão R.S. \& de Souza F.M. 2013. Symbiotic nitrogen-fixing bacterial populations trapped from soils under agroforestry systems in the Western Amazon. Scientia Agricola, 70(6): 397-404. DOI: https://doi.org/10.1590/S010390162013000600004AGR.

Jenkinson D.S. 1992. La materia orgánica del suelo: evolución. En: Wild A. Condiciones del suelo y desarrollo de las plantas. Mundi-Prensa. Madrid.
Kloepper J.W. 1993. Plant Growth-promoting rhizobacteria as biological control agents. In: Metting F.B. (Ed.) Soil Microbial Ecology: Applications in Agricultural and Environmental Management. 255-274. Marcel Dekker Inc., NY, USA.

Lara C., Oviedo L. \& Betancur C. 2011. Bacterias nativas con potencial en la producción de ácido indolacético para mejorar los pastos. Zootecnia tropical, 29(2): 187-194. http://www.bioline.org.br/pdf?zt11016.

Lara C., Villalba M. \& Oviedo L. 2007. Bacterias fijadoras asimbióticas de nitrógeno en la zona agrícola de San Carlos. Revista Colombiana de Biotecnología, 9(2): 6-14. https://revistas.unal.edu.co/index.php/biotecnologia/artic le/view/711.

León L.H. 2014. Determinación del potencial promotor del crecimiento vegetal de las enterobacterias aisladas de la rizósfera del cultivo de maíz (Zea mays L.). Scientia Agropecuaria, 5: 177-185. DOI: http://dx.doi.org/10.17268/sci.agropecu.2014.04.0 2 .

Liceta M. 2015. Aislamiento y caracterización de Pseudomonas y Bacillus provenientes de la rizósfera de diferentes variedades de quinua (Chenopodium quinoa Willd.) y su uso como potenciales promotoras del crecimiento vegetal. Tesis para optar el Título de Biólogo. Universidad Nacional Agraria La Molina. Lima, Perú. http://repositorio.lamolina.edu.pe/handle/UNALM/2690.

Marra L.M., Fonsêca C.R., de Oliveira S.M., Avelar P.M., Soares B.L., de Fráguas R., de Lima J.M. \& de Souza F.M. 2012. Biological nitrogen fixation and phosphate solubilization by bacteria isolated from tropical soils. Plant Soil, 357: 289-307. DOI : https://doi.org/10.1007/s11104-012-1157-z.

Martínez B., Obret Y., Pérez S. \& Reyes Y. 2014. Antagonismo in vitro de cepas de Trichoderma spp. frente a Sarocladium oryzae (Sawada) W. Gams \& D. Hawksworth. Revista de Protección Vegetal, 29(2): 106111.

http://revistas.censa.edu.cu/index.php/RPV/article/view/ 471.

Mehta P., Walia A., Kulshrestha S., Chauhan A. \& Shirkot C.K. 2015. Efficiency of plant growth-promoting Psolubilizing Bacillus circulans CB7 for enhancement of tomato growth under net house conditions. Journal Basis $\begin{array}{lll}\text { Microbiology, 55(1): 33-44. DOI: } & \end{array}$ https://doi.org/10.1002/jobm.201300562.

MycoBank. 2016. MycoBank DataBase. International Mycological Association. http://www.mycobank.org. Consultado el 20 de Setiembre del 2017.

Nautiyal C.S. 1999. An efficient microbiological growth medium for screening phosphate solubilizing microorganisms. FEMS Microbiology Letters, 170(1): 265-270. DOI: https://doi.org/10.1111/j.15746968.1999.tb13383.x.

Oliva C.E. 2015. Caracterización del potencial biológico de Bacillus spp. y sus metabolitos para el control de Colletotrichum acutatum causante de la antracnosis del chocho andino (Lupinus mutabilis) en las provincias de Chimborazo y Cotopaxi. Trabajo de Titulación presentado en conformidad con los requisitos establecidos para optar por el Título de Ingeniero en Biotecnología. Universidad de las Américas. URI: http://dspace.udla.edu.ec/handle/33000/4700. 
Ortiz C.P. 2013. Estudio de bacterias psicrótrofas aisladas de la zona de Junín con capacidad PGPR y su uso como potenciales biorremediadoras de metales pesados en una planta forrajera. Universidad Nacional Agraria La Molina. Lima, Perú. http://repositorio.lamolina.edu.pe/handle/UNALM/4313.

Pérez A., Rojas J. \& Fuentes J. 2010. Diversidad de bacterias endófitas asociadas a raíces del pasto colosuana (Bothriochloa pertusa) en tres localidades del departamento de Sucre, Colombia. Acta Biológica Colombiana, 15(2): 219-228. https://revistas.unal.edu.co/index.php/actabiol/article/vie w/12553.

Piontelli E. 2008. Aportes morfotaxonómicos en el género Aspergillus Link: Claves para las especies ambientales y clínicas más comunes. Boletín Micológico, 23: 49-66. DOI: https://doi.org/10.22370/bolmicol.2008.23.0.122.

Quiroz V.F., Ferrera R., Alarcón A. \& Lara M.E. 2008. Antagonismo in vitro de cepas de Aspergillus y Trichoderma hacia hongos filamentosos que afectan el cultivo del ajo. Revista Mexicana de Micología, 26: $27-$ 34. http://ref.scielo.org/9fd6z7.

Rosenblueth M. \& Martínez E. 2006. Bacterial Endophytes and their interactions with hosts. Molecular PlantMicrobe Interactions, 19(8): 827-837. DOI: https://doi.org/10.1094/mpmi-19-0827.

Sánchez D.B. 2011. Efecto de la inoculación con bacterias promotoras de crecimiento vegetal sobre el cultivo de tomate (Solanum lycopersicum var. Sofía) bajo invernadero. Trabajo de grado presentado como requisito para optar el Título de Master en Ciencias Biológicas. Pontificia Universidad Javeriana, Bogotá https://repository.javeriana.edu.co/bitstream/handle/105 54/1566/SanchezLopezDianaBeatriz2011.pdf?sequence $=1$.

Schwyn B. \& Neilands J.B. 1987. Universal chemical assay for the detection and determination of siderophores. Anal Biochem., 160(1): 47-56. DOI: https://doi.org/10.1016/0003-2697(87)90612-9.

Sørensen J. \& Sessitsch A. 2007. Plant-associated bacterialifestyle and molecular interactions. In: Van Elsas J.D., Jansson J.D. \& Trevors J.T. (eds) Modern soil microbiology. 211-236. 2nd Edition. CRC Press. USA.

Tapia M.E. 2015. El tarwi, lupino andino. Equipo técnico FADV Perú.

Tortora M.L., Salazar S.M., Díaz J.C., Guerrero M.F., Bellone C.H. \& Pedraza R.O. 2007. Actividad nitrogenasa y producción de sideróforos en cepas de Azospirillum brasilense aisladas de frutilla. En: Avances en la producción vegetal y animal del NOA, Argentina. 117-122. Universidad Nacional de Tucumán.
Trujillo I., Díaz A., Hernández A. \& Heydrich M. 2007. Antagonismo de cepas de Pseudomonas fluorescens y Burkholderia cepacia contra hongos fitopatógenos del arroz y el maíz. Revista de Protección Vegetal, 22(1): 4146.

http://scielo.sld.cu/scielo.php?script=sci_arttext\&pid=S1 010-27522007000100006.

Trujillo M.E., Alonso-Vega P., Rodríguez R., Carro L., Cerda E., Alonso P. \& Martínez-Molina E. 2010. The genus Micromonospora is widespread in legume root nodules: the example of Lupinus angustifolius. The ISME Journal, 4: $1265-1281$ DOI: https://doi.org/10.1038/ismej.2010.55.

Trujillo M.E., Kroppenstedt R.M., Schumann P. \& MartínezMolina E. 2006a. Kribella lupini sp. nov., isolated from the roots of Lupinus angustifolius International Journal of Systematic and Evolutionary Microbiology 56(2), 407411. DOI: https://doi.org/10.1099/ijs.0.63745-0.

Trujillo M.E., Kroppenstedt R.M., Schumann P., Carro L. \& Martínez-Molina E. 2006b. Micromonospora coriariae sp. Nov., isolated from rot nodules of Coriaria myrtifolia. International Journal of Systematic and Evolutionary Microbiology, 56(10): 2381-2385. DOI: https://doi.org/10.1099/ijs.0.64449-0.

Vega-Celedón P., Canchignia H., González M. \& Seeger M. 2016. Biosíntesis de ácido indol-3-acético y promoción del crecimiento de plantas por bacterias. Cultivos Tropicales, $\quad 37(5 \quad$ ESPECIAL): 33-39. http://scielo.sld.cu/scielo.php?script=sci_arttext\&pid=S0 258-59362016000500005.

http://ediciones.inca.edu.cu/index.php/ediciones/article/v iew/1186.

Vílchez G.J. 2017. Capacidad antagonista y promotora de del crecimiento vegetal de rizobacterias aisladas del cultivo de frijol (Phaseolus vulgaris L.). Tesis para optar el título de ingeniero agrónomo. Universidad Nacional Agraria La Molina. Perú. http://repositorio.lamolina.edu.pe/handle/UNALM/2681.

Weisburg W.G., Barns S.M., Pelletier D.A. \& Lane D.J. 1991. 16S Ribosomal DNA Amplification for phylogenetic study. Journal of Bacteriology, 173(2): 697703. DOI: https://doi.org/10.1128/jb.173.2.697703.1991.

Wilson K. 1997. Preparation of Genomic DNA from Bacteria. In: Ausubel F.M., Brent R., Kingston R.E., Moore D.D., Seidman J.G., Smith J.A. \& Struhl K. (eds.). 2003. Current Protocols in Molecular Biology, 2.4.12.4.5. John Wiley \& Sons, Inc. http://www.aun.edu.eg/molecular_biology/PCR(1)/Curr ent\%20Protocols\%20in\%20Mol.\%20Biol..pdf.

Zúñiga D. 2007. Control de fitopatógenos del cultivo de papa por bacterias antagónicas aisladas de la rizósfera del mismo cultivo. Informe técnico final. Proyecto 163-2006Concytec-OAJ. 
Tabla 2. Capacidades de promoción de crecimiento vegetal en los aislados bacterianos.

\begin{tabular}{|c|c|c|c|c|c|c|}
\hline Código & 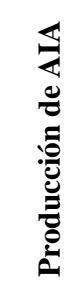 & 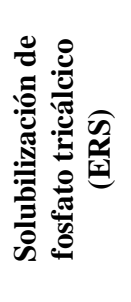 & 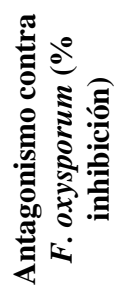 & 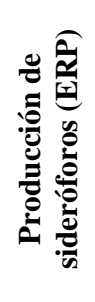 & 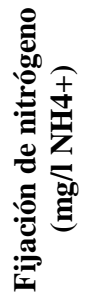 & Especie más cercana \\
\hline RB01 & +++ & 4.62 & - & 1.22 & n.d. & Achromobacter marplatensis \\
\hline RB02 & ++ & 3.82 & - & 2.91 & n.d. & Bacillus toyonensis \\
\hline RB03 & ++ & - & 23.24 & 2.27 & n.d. & \\
\hline RB05 & ++ & - & 17.01 & 3.54 & n.d. & \\
\hline RB06 & ++ & - & - & 2.50 & n.d. & \\
\hline RB08 & ++ & 3.47 & 10.79 & 5.00 & n.d. & Lysinibacillus macroides \\
\hline RB10 & ++ & 4.97 & 29.05 & 1.48 & n.d. & Bacillus circulans \\
\hline RB11 & ++ & - & 49.38 & 1.68 & n.d. & \\
\hline RB13 & ++ & - & - & 4.75 & n.d. & \\
\hline RB14 & +++ & 1.72 & - & 3.18 & n.d. & Bacillus cereus \\
\hline RB 15 & ++ & - & 28.22 & 1.64 & n.d. & \\
\hline RB16 & ++ & - & - & 2.62 & n.d. & \\
\hline RB 18 & ++ & - & - & 2.13 & n.d. & \\
\hline RB19 & ++ & - & - & 2.16 & n.d. & \\
\hline RB21 & ++ & - & - & 2.11 & n.d. & \\
\hline RB22 & ++ & 1.98 & - & 1.76 & n.d. & Paenibacillus polymyxa \\
\hline RB23 & ++ & - & 46.06 & 1.17 & n.d. & \\
\hline RB24 & ++ & - & 48.13 & 1.09 & n.d. & \\
\hline RB26 & ++ & - & 33.2 & 1.20 & n.d. & \\
\hline RAB02 & ++ & & 36.51 & - & n.d. & \\
\hline ТВ01 & ++ & 2.51 & - & 1.10 & n.d. & Enterococcus mundtii \\
\hline TB04 & ++ & - & - & 4.17 & n.d. & \\
\hline TB05 & +++ & 2.90 & - & 1.39 & n.d. & Lysinibacillus macroides \\
\hline NR01 & n.d. & n.d. & n.d. & n.d. & 8.47 & Bacillus cereus \\
\hline NR02 & n.d. & n.d. & n.d. & n.d. & 5.79 & Bacillus pumilus \\
\hline NR03 & n.d. & n.d. & n.d. & n.d. & 4.60 & Bacillus aryabhattai \\
\hline NR04 & n.d. & n.d. & n.d. & n.d. & 4.57 & Bacillus licheniformis \\
\hline NR05 & n.d. & n.d. & n.d. & n.d. & 6.02 & Bacillus pumilus \\
\hline NR06 & n.d. & n.d. & n.d. & n.d. & 8.04 & Bacillus liqueniformis \\
\hline
\end{tabular}

\footnotetext{
${ }^{1}$ Asistente de Investigación. Laboratorio de Biotecnología - Programa de Cereales y Granos Nativos / Universidad Nacional Agraria La Molina. Av. La Molina S/N, La Molina / Lima / Perú. lucero.26.1hs@ gmail.com.

${ }^{2}$ Profesora Principal. Departamento de Biología / Universidad Nacional Agraria La Molina. Av. La Molina s/n, La Molina / Lima / Perú. Autor de correspondencia: pamodisa@lamolina.edu.pe.

${ }^{3}$ Profesor Principal. Laboratorio de Biotecnología - Programa de Cereales y Granos Nativos / Universidad Nacional Agraria La Molina. Av. La Molina s/n, La Molina / Lima / Perú. jjimenezd@lamolina.edu.pe.
} 